\title{
Application of a recombinase polymerase amplification (RPA) assay and pilot field testing for Giardia duodenalis at Lake Albert, Uganda
}

Sandra J. Molina-Gonzalez ${ }^{1,2+}$, Tapan Bhattacharyya ${ }^{2,3{ }^{*}{ }^{+}}$, Hajri R. AlShehri ${ }^{4,5}$, Kate Poulton $^{2,6}$, Stephen Allen ${ }^{7}$, Michael A. Miles ${ }^{2,3}$, Moses Arianitwe ${ }^{8}$, Edridah M. Tukahebwa ${ }^{8}$, Bonnie Webster ${ }^{2,6}$, J. Russell Stothard ${ }^{4}$ and Amaya L. Bustinduy ${ }^{1,2+}$

\begin{abstract}
Background: Giardia duodenalis is a gastrointestinal protozoan causing 184 million cases of giardiasis worldwide annually. Detection is by microscopy or coproantigen assays, although sensitivity is often compromised by intermittent shedding of cysts or trophozoites, or operator expertise. Therefore, for enhanced surveillance field-applicable, point-of-care (POC), molecular assays are needed. Our aims were to: (i) optimise the recombinase polymerase amplification (RPA) assay for the isothermal amplification of the G. duodenalis $\beta$-giardin gene from trophozoites and cysts, using published primer and probes; and (ii) perform a pilot field validation of RPA at a field station in a resource-poor setting, on DNA extracted from stool samples from schoolchildren in villages around Lake Albert, Uganda. Results were compared to an established laboratory small subunit ribosomal RNA (SSU rDNA) qPCR assay with additional testing using a qPCR targeting the triose phosphate isomerase (tpi) DNA regions that can distinguish G. duodenalis of two different assemblages (A and B), which are human-specific.

Results: Initial optimisation resulted in the successful amplification of predicted RPA products from G. duodenalispurified gDNA, producing a double-labelled amplicon detected using lateral flow strips. In the field setting, of 129 stool samples, 49 (37.9\%) were positive using the Giardia/Cryptosporidium QuikChek coproantigen test; however, the RPA assay when conducted in the field was positive for a single stool sample. Subsequent molecular screening in the laboratory on a subset $(n=73)$ of the samples demonstrated better results with 21 (28.8\%) RPA positive. The SSU rDNA qPCR assay resulted in 30/129 (23.3\%) positive samples; 18 out of 73 (24.7\%) were assemblage typed (9 assemblage A; 5 assemblage B; and 4 mixed A+B). Compared with the SSU rDNA qPCR, QuikChek was more sensitive than RPA (85.7 vs $61.9 \%$ ), but with similar specificities (80.8 vs $84.6 \%$ ). In comparison to QuikChek, RPA had $46.4 \%$ sensitivity and $82.2 \%$ specificity.

Conclusions: To the best of our knowledge, this is the first in-field and comparative laboratory validation of RPA for giardiasis in low resource settings. Further refinement and technology transfer, specifically in relation to stool sample preparation, will be needed to implement this assay in the field, which could assist better detection of asymptomatic Giardia infections.
\end{abstract}

\footnotetext{
*Correspondence: tapan.bhattacharyya@lshtm.ac.uk

†Sandra J. Molina-Gonzalez, Tapan Bhattacharyya and Amaya L. Bustinduy contributed equally to this work

${ }^{3}$ Department of Infection Biology, London School of Hygiene \& Tropical Medicine, London, UK

Full list of author information is available at the end of the article
}

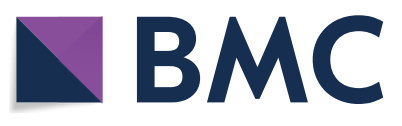

(c) The Author(s) 2020. This article is licensed under a Creative Commons Attribution 4.0 International License, which permits use, sharing, adaptation, distribution and reproduction in any medium or format, as long as you give appropriate credit to the original author(s) and the source, provide a link to the Creative Commons licence, and indicate if changes were made. The images or other third party material in this article are included in the article's Creative Commons licence, unless indicated otherwise in a credit line to the material. If material is not included in the article's Creative Commons licence and your intended use is not permitted by statutory regulation or exceeds the permitted use, you will need to obtain permission directly from the copyright holder. To view a copy of this licence, visit http://creativecommons.org/licenses/by/4.0/. The Creative Commons Public Domain Dedication waiver (http://creativecommons.org/publicdomain/zero/1.0/) applies to the data made available in this article, unless otherwise stated in a credit line to the data. 
Keywords: Giardia duodenalis, Giardia intestinalis, Giardia lamblia, Point-of-care, Recombinase polymerase amplification, Giardiasis, Assemblage typing, Uganda, Epidemiology

\section{Background}

Giardia duodenalis (syns G. lamblia and G. intestinalis) is a flagellated protozoan parasite of the human gastrointestinal tract as well as a range of other mammals worldwide. It is acquired by ingestion of viable cysts present in faecal-contaminated water, food or on fomites [1]. Ingested cysts undergo excystation into actively multiplying trophozoites in the duodenum, which attach to the intestine causing epithelial inflammation, villous flattening and malabsorption. Symptoms include acute or chronic diarrhoea, weight loss and impaired development in children [1,2]. The encysted stage is passed in stools [2]. Symptomatic giardiasis results in around 184 million clinical cases globally per year. Giardia duodenalis infection can be asymptomatic and undetected carriers remain a source of infection. On the basis of molecular characterisation, G. duodenalis is divided into eight genetic assemblages $(\mathrm{A}-\mathrm{H})$, of which $\mathrm{A}$ and $\mathrm{B}$ are considered human-specific [3]; thus, it is important to identify which assemblages are present during validation of any new molecular diagnostic based on species-specific DNA loci.

Detection of G. duodenalis is routinely carried out by identifying cysts or trophozoites in faeces using direct microscopy, with variable sensitivity and specificity. These methods can be labour-intensive, requiring multiple examinations or involve complicated concentration procedures best performed by experienced technicians $[4,5]$. Immunological and molecular techniques have achieved better sensitivity of $79-100 \%$ [6] but specificity can be reduced. A drawback of molecular assays is often the need for expensive and sophisticated equipment that is not available in resource-poor endemic settings. Giardiasis is particularly common in Uganda [7]. Al-Shehri et al. [8] reported a prevalence of G. duodenalis infection at $42 \%(40 / 96)$ using the rapid QuikChek coproantigen test and $87 \%(221 / 254)$ by qPCR in Ugandan children (5-10 years-old), with many heavy infections.

Unlike conventional PCR-based methods, recombinase polymerase amplification (RPA) is an isothermal amplification system that is rapid and requires only basic and portable equipment [9] making it feasible for the point-of-care (POC) diagnosis of tropical diseases in low resource endemic settings. Crannell et al. [10] developed an RPA assay for G. duodenalis amplifying a fragment of the $\beta$-giardin gene. Here, we further optimised this RPA assay for G. duodenalis for use in a resource-poor setting, and tested its applicability at a field station in a remote rural area near Lake Albert, Uganda, highly endemic for giardiasis. Additionally, we utilised the commercially available Giardia/Cryptosporidium QuikChek coproantigen test (Abbott, Maidenhead, UK), in the field to investigate the prevalence of giardiasis in a cohort of children from the endemic area of Lake Albert. Samples from this cohort were also analysed using the small subunit ribosomal RNA gene (SSU rDNA) qPCR assay for Giardia and also the triose phosphate isomerase (tpi) qPCR assay to enable discrimination of assemblage A and B G. duodenalis [11]. RPA and the QuikChek coproantigen test were compared against the $S S U$ rDNA qPCR as the 'gold standard.

\section{Methods \\ Laboratory RPA optimisation \\ Giardia duodenalis genomic DNA controls}

Cryopreserved G. duodenalis trophozoite pellets, assemblage A (sourced from the London School Hygiene and Tropical Medicine (LSHTM), London, UK) and G. duodenalis cysts H-3 (human isolate, assemblage B; P101, Waterborne Inc., New Orleans, USA) were used as sources of control DNA for the testing of the RPA and qPCR assays. The control DNA samples were extracted using the QIAamp DNA Mini Kit (51304; Qiagen, Manchester, UK), with modifications: cells were mixed with 1 $\mathrm{ml}$ of NucliSENS lysis buffer (supplied as containing 50\% guanidine thiocyanate, $<2 \%$ Triton X-100, $<1 \%$ EDTA) (200292; BioMerieux, Basingstoke, UK) and Precellys Soil Mix beads SK38 (03961-1-006; Stretton Scientific, Stretton, UK). Samples were vortexed for $5 \mathrm{~min}$, and incubated at room temperature for $20 \mathrm{~min}$. Beads and debris were pelleted by centrifugation at $14,000 \times \mathrm{rpm}$ for $2 \mathrm{~min}$. Two hundred microliters of supernatant was transferred to a clean microcentrifuge tube and the manufacturer's protocol for the Qiagen 51304 QIAamp DNA Mini Kit was followed thereafter, with the DNA being eluted in $200 \mu \mathrm{l}$ of AE buffer (10 mM Tris-Cl, $0.5 \mathrm{mM}$ EDTA; $\mathrm{pH}$ 9.0).

\section{Recombinase polymerase amplification (RPA) and lateral flow G. duodenalis assay}

All primer and probe sequences used were as previously described [10] (Additional file 1: Table S1). Figure 1a depicts the binding locations on the RPA probes and primers for the $\beta$-giardin gene.

Three different areas in the laboratory were assigned for (i) the RPA master mix preparation, (ii) the addition of DNA, and (iii) the RPA reaction and lateral flow amplicon detection in a laminar flow hood. This was done to 


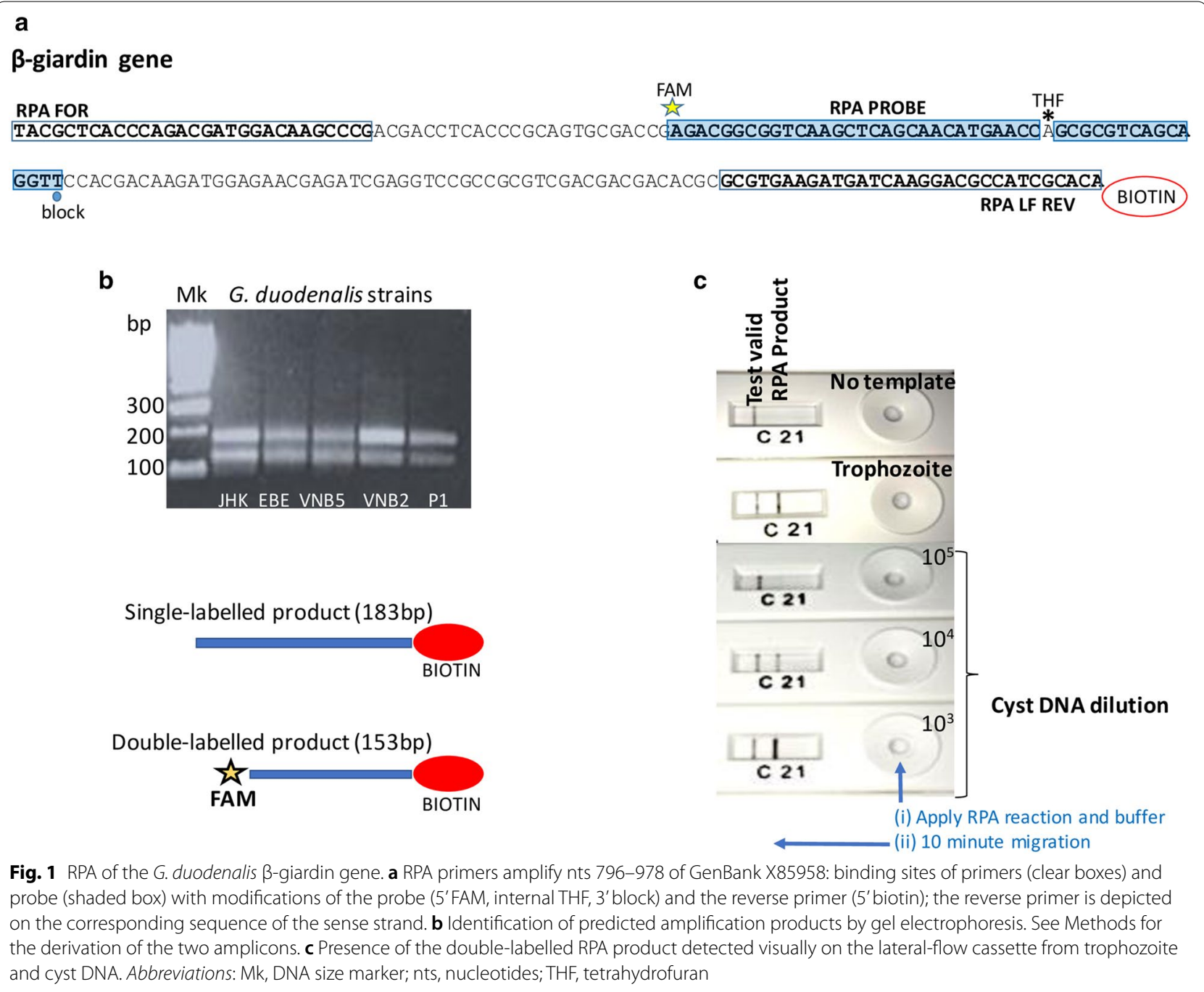

prevent cross-contamination and false positives. Reactions were performed using the TwistAmp nfo kit (TANFO02KIT; TwistDx, Maidenhead, UK) in a final volume of $50 \mu \mathrm{l}$. The master mix consisted of $29.5 \mu \mathrm{l}$ of rehydration buffer, $2.1 \mu \mathrm{l}$ of $10 \mu \mathrm{M}$ forward primer, $2.1 \mu \mathrm{l}$ of $10 \mu \mathrm{M}$ reverse primer, $0.6 \mu \mathrm{l}$ of $10 \mu \mathrm{M}$ probe, $7.5 \mu \mathrm{l}$ of $5 \mathrm{M}$ betaine $(720 \mathrm{mM})$ (B0300; Sigma-Aldrich, Gillingham, UK) and $2.5 \mu \mathrm{l}$ of $\mathrm{H}_{2} \mathrm{O}$. The RPA nfo pellets were transferred to sterile individually capped $0.2 \mathrm{ml}$ tubes, to which $37.5 \mu \mathrm{l}$ of master mix was added. Then, $2.5 \mu \mathrm{l}$ of $280 \mathrm{mM}$ magnesium acetate was added to the inside wall of each tube. Ten microlitres of extracted DNA was added to the tubes, which were then inverted manually 8 to 10 times and centrifuged briefly. Negative controls (no template) were incorporated into each set of reactions.

Reactions were incubated at $37^{\circ} \mathrm{C}$ for $30 \mathrm{~min}$ in a thermal cycler (Applied Biosystems 9700). At minutes 4 and 15 of the incubation, the tubes were removed from the cycler, inverted manually 8 to 10 times and then centrifuged briefly before being returned to $37^{\circ} \mathrm{C}$. After $30 \mathrm{~min}$ of incubation, the reactions were immediately placed at $4{ }^{\circ} \mathrm{C}$. Rapid detection of the FAM-biotin double-labelled amplification product was visualised using lateral flow Milenia Genline HybriDetect (MGHD) strips in a dipstick format and also the PCRD Nucleic Acid Detector lateral flow cassettes (Abingdon Health, York, UK). Detections using the MGHD strips were performed by adding $2 \mu \mathrm{l}$ of the RPA reaction to $98 \mu$ l of supplied detection buffer, into which the strips were then placed; after 5 min of incubation at room temperature the results were assessed visually as positive or negative by the presence or absence of the test line. For the PCRD cassettes, the following manufacturer's recommendations were used: $5 \mu$ l of the RPA reaction was added to $70 \mu$ of the cassette running buffer; the whole $75 \mu \mathrm{l}$ was then added to the PCRD cassette window and incubated at room temperature for 10 
min. These assays were also assessed visually by the presence or absence of the test line.

Successful RPA reactions were also assessed by electrophoresis of the reaction products. Amplicons were column-purified (28104: Qiagen) and then run on a 2\% agarose gel to check for specific amplification of the 153 bp amplicon, i.e. the double-labelled RPA product.

\section{Field assessment at Lake Albert, Uganda Stool collection}

Single stool samples were collected from primary school children in three Ugandan villages on the shore of Lake Albert. Participant children were randomly selected from schools where studies of intestinal schistosomiasis were ongoing [12]. A field station laboratory was set up nearby at the Bugoigo research camp consisting of a small building with separate areas for DNA extraction from the stool samples, RPA preparation and amplicon detection. The field station was equipped with all the necessary resources for performing the stool DNA extractions and the RPA with electricity supplied by means of a portable generator. An aliquot of fresh stool $(c .500 \mu \mathrm{l})$ was homogenized with PBS (1:1). A second aliquot of stool was prepared by homogenizing $500 \mu \mathrm{l}$ of fresh faeces with $500 \mu \mathrm{l}$ of $70 \%$ ethanol, in a $2.0 \mathrm{ml}$ screw-cap tube; these aliquots were stored for later testing as described below.

\section{Coproantigen test}

An aliquot of stool was also tested at the field station with the commercially available Giardia/Cryptosporidium QuikChek coproantigen test (Abbott), according to manufacturer's instructions. Briefly, the stool sample was added to the supplied diluent/conjugate mixture, transferred to the test cassette containing anti-Giardia monoclonal antibodies, and after addition of the supplied wash buffer and substrate, results were read visually.

\section{Field stool DNA extraction for RPA}

DNA was extracted from each stool sample homogenized in PBS using the QIAamp DNA Mini Kit (51304; Qiagen). Approximately $200 \mathrm{mg}$ of the stool samples were transferred to a $2 \mathrm{ml} \mathrm{screw-cap} \mathrm{tube} \mathrm{containing} 1 \mathrm{ml}$ of the NucliSENS lysis buffer and Precellys Soil Mix beads SK38. Samples were vortexed for $5 \mathrm{~min}$, and incubated at room temperature for $20 \mathrm{~min}$. Beads and debris were collected in a pellet by centrifugation at $14,000 \times \mathrm{rpm}$ for $2 \mathrm{~min}$. Two hundred microliters of the supernatant was transferred to a clean microcentrifuge tube and the manufacturer's protocol was followed thereafter. DNA was eluted in $200 \mu \mathrm{l}$ of AE buffer.

\section{Field RPA analysis}

RPA assays were performed in the field using the assay conditions as described above, except that $0.7 \mu \mathrm{l}$ of $5 \mathrm{M}$ betaine $(70 \mathrm{mM})$ was added for each reaction. Amplification was carried out at $37^{\circ} \mathrm{C}$ using a dry block heater (SP2280; SciQuip, Wem, UK). Detection of amplicons was performed using PCRD Nucleic Acid Detector lateral flow cassettes as described above.

\section{Subsequent laboratory testing of the field samples at LSHTM Stool DNA extraction}

Stool samples that had been stored in ethanol were washed 3 times with PBS and then extracted using the QIAamp DNA Stool Mini Kit (51504; Qiagen) following the manufacturer's protocol, and eluted in $200 \mu \mathrm{l}$ of supplied buffer AE. The DNA concentration was determined using a Nanodrop ND-1000 spectrophotometer (Thermo Fisher Scientific, Paisley, UK). The use of this kit, an alternative to the QIAamp DNA Mini Kit used in the original Giardia RPA assay published by Crannell et al. [10] and in this work at the Lake Albert field station, was employed here to remove potential inhibitors from the samples for downstream molecular assays. These assays were: RPA (as detailed above); assemblage-specific qPCR (tpi gene); and non-assemblage specific SSU qPCR test.

\section{Assemblage-specific qPCR assays}

The assemblage-specific multiplex qPCR [11] was performed on individual samples. Primers and probes are listed in Additional file 1: Table S1 and binding sites are shown in Additional file 2: Figure S1. Each reaction was performed in a total volume of $20 \mu \mathrm{l}$, and comprised 10 $\mu \mathrm{l}$ of $2 \times$ reaction mix (B20.23-01; PCR Biosystems, London, UK), $0.8 \mu \mathrm{l}$ of a $10 \mu \mathrm{M}$ solution of each forward and reverse primer for assemblage $A$ and $B, 0.4 \mu \mathrm{l}$ of a $10 \mu \mathrm{M}$ solution of each assemblage (A and B) probe, $4.4 \mu \mathrm{l}$ of DNA, and $1.6 \mu \mathrm{l}$ of $\mathrm{ddH}_{2} \mathrm{O}$. Samples were run on a RotorGene 3000 machine (Corbett Research, Mortlake, Australia) using the following cycling conditions: 1 cycle at $95^{\circ} \mathrm{C}$ for 2 mins; 40 cycles at $95^{\circ} \mathrm{C}$ for $5 \mathrm{~s}$ and $60^{\circ} \mathrm{C}$ for 30 s. Each qPCR run included positive controls containing DNA extracted from trophozoite (assemblage A) and cyst (assemblage B). Thresholds to calculate $\mathrm{Cq}$ values were set compared to water controls in each run. Negative (no template) reactions were run with each set of reactions.

\section{SSU rDNA $q P C R$}

The $S S U$ rDNA qPCR was performed on the same DNA extracts as described above using the primer and probe sequences as previously described $[13,14]$. The primers 
and probe are listed in Additional file:1: Table S1 and binding sites are shown in Additional file 2: Figure S1. Reactions were performed in a total volume of $20 \mu \mathrm{l}$, and comprised $10 \mu \mathrm{l}$ of $2 \times$ reaction mix (B20.23-01; PCR Biosystems), $0.8 \mu \mathrm{l}$ of a $10 \mu \mathrm{M}$ solution of each primer, 0.4 $\mu \mathrm{l}$ of a $10 \mu \mathrm{M}$ solution of probe, $5 \mu \mathrm{l}$ of DNA, and $3 \mu \mathrm{l}$ of $\mathrm{dd}_{2} \mathrm{O}$. Samples were run on a Rotor-Gene 3000 as described above.

\section{Statistical tests}

Confidence intervals (95\% CI) for sensitivity and specificity comparisons of $S S U$ rDNA qPCR, RPA and QuikChek were calculated using Graphpad QuickCalcs (https:// www.graphpad.com/quickcalcs/ConfInterval1.cfm).

Receiver operating characteristic (ROC) curves for comparing RPA and the QuikChek coproantigen test against the $S S U$ rDNA qPCR as the 'gold standard' were calculated using easyRoc v1.3.1 (http://www.biosoft.hacet tepe.edu.tr/easyROC/). $P$-values of $<0.05$ were considered significant.

\section{Results}

\section{RPA optimisation at LSHTM}

As shown in Fig. 1b, the RPA with DNA extracted from the G. duodenalis cultures generated amplicons of the predicted sizes from the $\beta$-giardin gene. The 153-bp FAM-biotin double-labelled product could be reliably identified by the PCRD lateral flow cassette; cyst DNA diluted to $10^{4}$ (approximately $6 \mathrm{ng} / \mu \mathrm{l}$ ) generated RPA products detectable by lateral flow and confirmed by gel electrophoresis (Fig. 1c). As predicted from the binding sites of the RPA primers and probe (Fig. 1a), two amplicons were produced: the 153-bp double-labelled amplicon produced by the RPA probe with primer RPA LF REV; and the 183-bp amplicon produced by primers RPA FOR and RPA LF REV. As described by Piepenburg et al. [9] the RPA probe binds the 183-bp amplicon, allowing nfo endonuclease to expose a 3'-OH, and Bsu polymerase to generate the 153-bp double-labelled amplicon. We observed, during our initial optimisation phase that the MGHD strips were prone to producing false-positive results from water (no template) controls, and thus were not well suited for field application, so the use of those strips was discontinued and the PCRD cassettes were utilised. Another crucial modification during the optimisation was the addition of betaine into the RPA reaction mix, following determination of optimal concentration via titration. This reagent was used to prevent the formation of false-positive products generated in no-template controls due to secondary structure formation by the primers and probe.

\section{Assays performed at the field station}

The location and lakeshore environment of Bugoigo are shown Fig. 2a. The equipment used at the field station laboratory (including a microcentrifuge for spin-column DNA extraction and a dry heating block for isothermal incubation of RPA reactions) functioned reliably, allowing a total of 129 collected stool samples to be assayed. RPA gave positive results using control DNA from purified trophozoites, and also a single stool sample extracted in the field (Fig. 2b). However, the remaining samples extracted and tested in the field were negative by RPA, with no false-positives observed. Forty-nine stool samples from the 129 examined (37.9\%) were positive using the Giardia/Cryptosporidium QuikChek (Table 1).

\section{Subsequent assays performed at LSHTM on the field samples extracted using the QIAamp DNA Stool Mini Kit} Of the 129 samples tested $30(23.25 \%)$ were positive for G. duodenalis by SSU rDNA qPCR (Table 1). Due to resource limitations, only a subset of 73 samples could be assayed by RPA at LSHTM. Of these, 21 (28.8\%, 95\% CI: 19.6-40.1\%) were RPA-positive; 13 (17.8\%, 95\% CI: $10.6-$ $28.3 \%$ ) were positive by both RPA and the SSU rDNA qPCR (Table 2); and 10 (13.7\%, 95\% CI: 7.4-23.6\%) were positive by all three assays, QuikChek coproantigen, SSU rDNA qPCR and RPA.

Within this subset, considering the $S S U$ rDNA qPCR ( $n=21$ positive) as the 'gold standard', the QuikChek coproantigen test $(18 / 21$; 85.7\%, 95\% CI: $64.5-95.8 \%)$ was more sensitive than RPA $(13 / 21,61.9 \%, 95 \%$ CI: $40.1-79.3 \%)$, but with a similar specificity $(80.8 \%, 95 \% \mathrm{CI}$ : 67.9-89.4\% vs 84.6\%, 95\% CI: 72.2-92.2\%, respectively) (Table 2). Compared to the QuikChek coproantigen test, RPA had a sensitivity of $46.4 \%$ (95\% CI: $29.5-64.2 \%)$ and a specificity of $82.2 \%$ (95\% CI: 68.4-90.1\%) (Table 3). Figure 3 shows the corresponding ROC curves for the gold standard SSU rDNA qPCR. For RPA, the area under the curve (AUC) was 0.73 (95\% CI: 0.62-0.85) $(P=0.0001)$ and for QuikChek the AUC was 0.83 (95\% CI: 0.74-0.93) $(P<0.0001)$.

For the G. duodenalis assemblage A and B qPCR, from the subset of 73 samples tested, assemblage typing was performed for 18 (24.7\%) of the samples and characterised as: 9 samples as assemblage A; 5 samples as assemblage $B$; and 4 samples were of mixed assemblage infections for $\mathrm{A}$ and $\mathrm{B}$.

\section{Discussion}

In this study we found the RPA assay, when tested in the laboratory at the LSHTM, to have $61.9 \%$ sensitivity and $84.6 \%$ specificity, compared to the gold standard SSU rDNA qPCR for detecting G. duodenalis in faecal samples collected from school children in endemic villages 

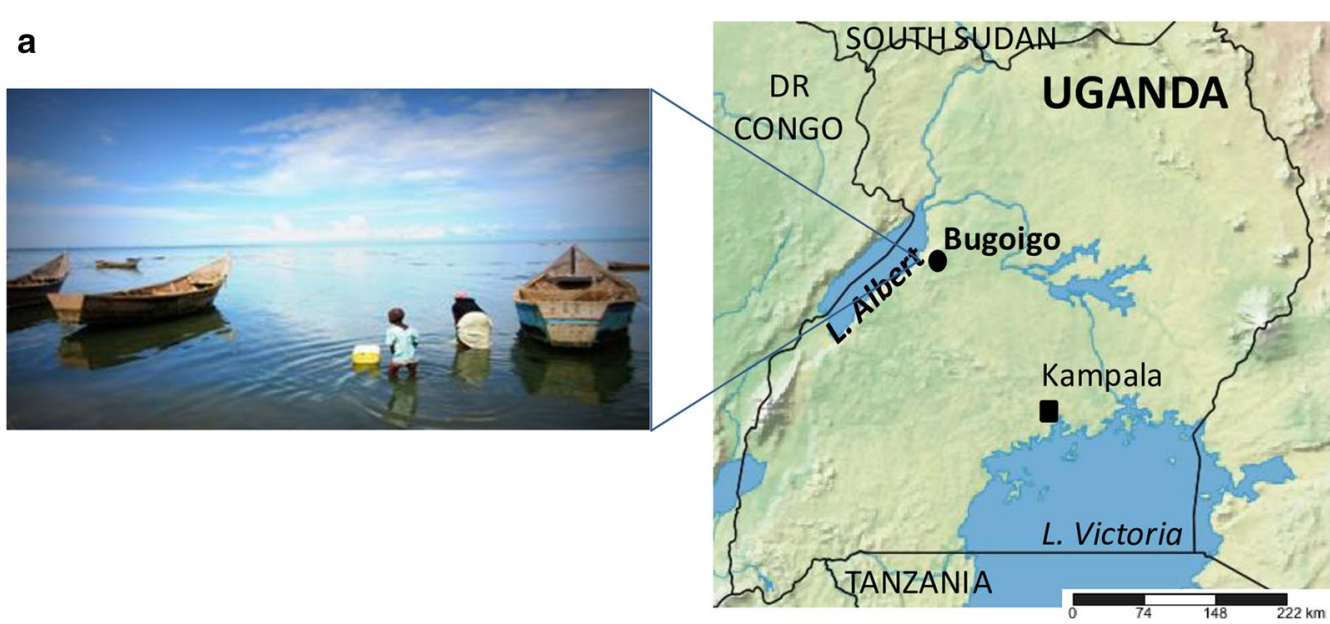

b

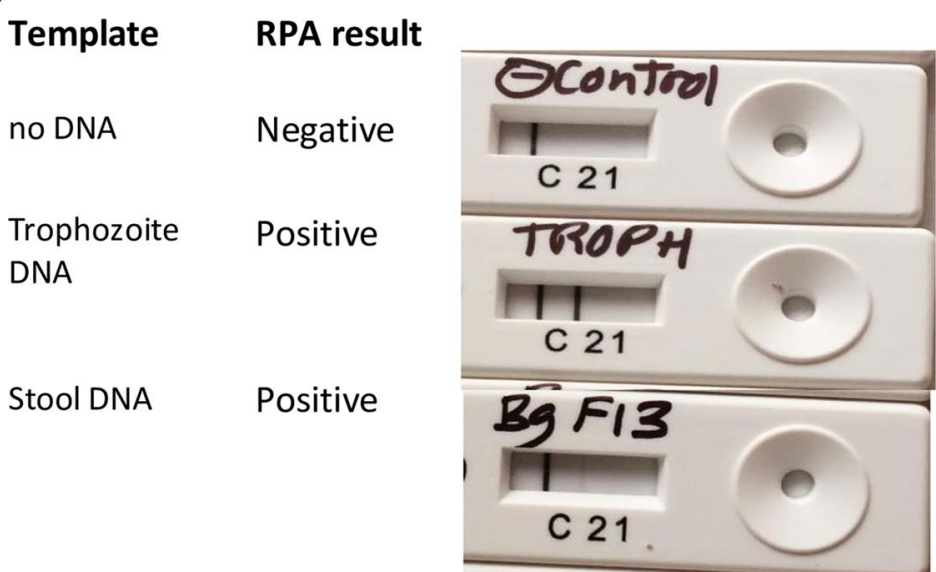

Fig. 2 Lake Albert field setting. a Map of Uganda showing the location of the Bugoigo field site and lakeshore environment. b RPA under field conditions gave positive results for control DNA from G. duodenalis trophozoites and a stool sample. Photo credit: A. Bustinduy. Map source: http:// www.simplemappr.net

Table 1 Results of field samples assayed by QuikChek and SSU rDNA qPCR for Giardia $(n=129)$

\begin{tabular}{lll}
\hline & Positive & Negative \\
\hline QuikChek & 49 & 80 \\
SSU qPCR & 30 & 99 \\
\hline
\end{tabular}

Table 2 Results comparing QuikChek and RPA with SSU rDNA qPCR $(n=73)$

\begin{tabular}{llll}
\hline & & \multicolumn{2}{l}{ SSU rDNA qPCR } \\
\cline { 3 - 4 } & & Positive & Negative \\
\hline QuikChek & Positive & 18 & 10 \\
\multirow{2}{*}{ RPA } & Negative & 3 & 42 \\
& Positive & 13 & 8 \\
& Negative & 8 & 44 \\
\hline
\end{tabular}

Table 3 Results comparing QuikChek and RPA $(n=73)$

\begin{tabular}{llll}
\hline & & QuikChek & \\
\cline { 3 - 4 } & & Positive & Negative \\
\hline RPA & 13 & 8 \\
& Positive & 15 & 37
\end{tabular}

around Lake Albert, Uganda. We have demonstrated here that the RPA assay can be used to amplify and detect specific DNA regions of $G$. duodenalis within faecal extracts, and that the assay is transposable to field station facilities, albeit with scope for further development, specifically in relation to the sample preparation. Crannell et al. [10] first developed the $\beta$-giardin RPA assay for G. duodenalis, which was assessed on spiked stool samples from healthy subjects and on samples from children in Peru, reporting $73 \%$ sensitivity against a gold standard of positivity 

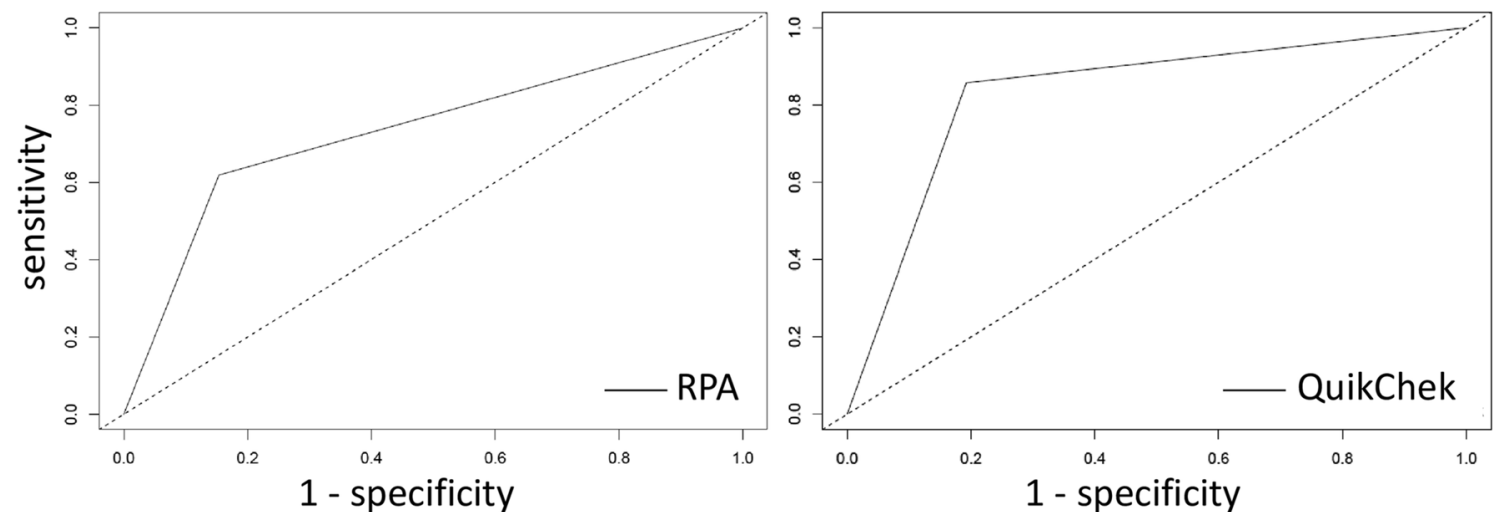

Fig. 3 ROC curves of RPA and QuikChek against SSU rDNA qPCR

by qPCR or microscopy, but acknowledged that the assay required further improvement and validation under field conditions.

Of note, during the course of this study, we encountered several unexpected technical issues, relating to faecal DNA extraction and subsequent RPA reaction and detection. Stool samples contain many inhibitors that are detrimental to molecular assays and it is crucial to reduce their presence as much as possible. Furthermore, faecal matter and Giardia cysts may require additional physical disruption to facilitate DNA extraction. The use of both the QIAamp DNA Mini Kit and QIAamp DNA Stool Mini Kit has been reported in the literature for stool Giardia DNA extraction. Initially during the RPA optimisation phase at LSHTM and at the Bugoigo field station, we used the QIAamp DNA Mini Kit in a modified protocol that included preliminary steps employing soil mix beads and NucliSENS lysis buffer prior to standard extraction protocol. For better field applicability, the possible effects on DNA extraction of local temperature and humidity should be considered. However, as an alternative method, we later changed to the QIAamp DNA Stool Mini Kit which greatly increased the performance of the RPA assay.

Additionally, the combination of betaine in the reaction mix and the use of the PCRD cassettes for detection [15], rather than the MGHD strips reported previously for this Giardia RPA [10], greatly increased the reliability of the RPA technique in our hands. We found that in the initial laboratory optimisation, the RPA assays without betaine were susceptible to giving false positives, although this could be controlled by using a concentration of $720 \mathrm{mM}$ betaine with purified culture DNA; however, as this may have suppressed weak positives from stool-extracted DNA, we found after serial titration of spiked stool that this could be decreased to $70 \mathrm{mM}$ for stool-extracted
DNA. However, we cannot discount the possibility that the use of betaine may have also decreased the sensitivity of the assay. The AUC values from ROC curve analysis are encouraging, with scope for further optimisation. A future development of the RPA approach applied here to Giardia DNA would be the use of real time fluorescent RPA assays (TwistAmp exo; TwistDx). This uses a fluorescent probe that can be detected during DNA amplification and reactions can be run in small portable temperature-controlled fluorescence readers. These assays have also been reported to be more sensitive, have a reduced risk of cross-contamination and are more straightforward to carry out [16]. However, sample preparation is key for assay robustness and the need for the equipment needed for the extraction kits used reduces the field applicability of the RPA assay.

Giardia duodenalis subspecies assemblages A and B are considered to be human-specific [3]. Studies that have associated assemblage with clinical manifestations have not revealed a straightforward relationship, and there are conflicting reports from different settings of assemblages $\mathrm{A}$ or $\mathrm{B}$ being associated with diarrhoea and other symptoms [17]. The assemblage A- and B- specific qPCRs used here were first reported on giardiasis cases in the UK [11], with this same method later used on Ugandan [18] and Cambodian samples [19]. Assemblage typing from Ugandan human samples has reported assemblages A and B in single and mixed infections [18, 20-23]. Additional file 3: Figure S2 maps the assemblage typing from human samples from the present study and from the five previous reports, which have used the $t p i$ gene and other genetic targets. As seen in the previous studies, we detected both assemblages A and B circulating in human populations in Uganda, and here in the Lake Albert environment. In addition to disease surveillance, this RPA assay may also be applicable to monitor 
therapeutic outcome of treatment and also to detection Giardia in faecal samples from infected animals.

\section{Study limitations}

There are some limitations of this study. Issues relating to the extraction of high-purity DNA from stool samples impeded the field validations and should be further investigated, including alternative, more streamlined, methods for DNA extraction, such as that used for RPA with bovine stool samples [24], with emphasis on standardisation for field application. The absolute limit of detection of stool-extracted Giardia DNA by the RPA used in the present study should be fully determined, particularly in relation to that for SSU rDNA qPCR. Additionally, validation is needed on a set of well-defined clinical samples containing other gastro-intestinal pathogens to evaluate assay specificity, although the RPA-amplified sequence is specific to G. duodenalis by NCBI BLAST search.

\section{Conclusions}

We have shown here that RPA can be applied successfully for the detection of Giardia DNA in field-collected stool samples for disease surveillance; however further optimisation of sample preparation, particularly with regard to DNA extraction from stool samples are required to make this RPA more suitable as point-of-care test, prior to subsequent field validations.

\section{Supplementary information}

Supplementary information accompanies this paper at https://doi. org/10.1186/s13071-020-04168-1.

\begin{abstract}
Additional file 1: Table S1. Sequences of primers and probes for the RPA and qPCR assays.

Additional file 2: Figure S1. Giardia duodenalis qPCR targets. The figure shows the binding sites of primers (clear boxes) and probes (shaded boxes). Reverse primers are depicted on the corresponding sequence on the sense strand. a Assemblage specific qPCR of the tpi gene. The last either three or four bases at the $3^{\prime}$ end of the forward and reverse primers exploit assemblage $A$ and $B$-specific polymorphisms of tpi and enable discrimination between assemblage $A$ and $B$ : assemblage A GDAT probe has 5' VIC and 3' BHQ1; assemblage B GDBT probe has 5'FAM and 3'NFQ. b Non-assemblage specific qPCR of the SSU rRNA gene: SSU probe has 5' JOE and 3'BHQ1. Abbreviations: FAM, JOE, VIC, fluorescent dyes; BHQ1, black hole quencher 1; NFQ, non-fluorescent quencher; nts, nucleotides; tpi, triose phosphate isomerase.
\end{abstract}

Additional file 3: Figure S2. Reports of G. duodenalis assemblage typing from Ugandan human samples. Numbers in brackets refer to cited reference list in main manuscript. Abbreviation: NP, National Park.

\section{Acknowledgements}

At LSHTM we thank Debbie Nolder for providing the Giardia trophozoites, and Chrissy Roberts and Robert Butcher for access to laboratory facilities.

\section{Authors' contributions}

ALB and JRS conceived the study; SJMG, TB, HAS and ALB performed the work and acquired the data. SJMG, TB and ALB wrote the manuscript. KP, SA, MA, EMT, MAM, BW and JRS provided methodological input, and contributed to writing the manuscript. All authors read and approved the final manuscript.

\section{Funding}

This work was funded by a UK Medical Research Council Confidence-inConcept grant to ALB. The funding body had no role in the design of the study and collection, analysis, and interpretation of data and in writing the manuscript.

\section{Availability of data and materials}

The dataset supporting the conclusions of this article is included within the article and its additional files.

\section{Ethics approval and consent to participate}

This study (CiC160430AB17) was approved by the respective Ethics Committees of the Liverpool School of Tropical Medicine and the London School of Hygiene and Tropical Medicine (LSHTM), UK (Ref: 12034), and the Vector Control Division, Ministry of Health, Uganda.

\section{Consent for publication}

Not applicable.

\section{Competing interests}

The authors declare that they have no competing interests.

\section{Author details}

${ }^{1}$ Department of Clinical Research, London School of Hygiene \& Tropical Medicine, London, UK. ${ }^{2}$ London Centre for Neglected Tropical Disease Research, London, UK. ${ }^{3}$ Department of Infection Biology, London School of Hygiene \& Tropical Medicine, London, UK. ${ }^{4}$ Department of Parasitology, Liverpool School of Tropical Medicine, Liverpool, UK. ${ }^{5}$ Ministry of Health, Asir District, Abha, Kingdom of Saudi Arabia. ${ }^{6}$ Natural History Museum Parasites and Vectors Division, Life Sciences Department, London, UK. ${ }^{7}$ Department of Clinical Sciences, Liverpool School of Tropical Medicine, Liverpool, UK. ${ }^{8}$ Vector Control Division, Ministry of Health, Kampala, Uganda.

Received: 14 January 2020 Accepted: 2 June 2020

Published online: 06 June 2020

\section{References}

1. Minetti C, Chalmers RM, Beeching NJ, Probert C, Lamden K. Giardiasis. BMJ. 2016;355:i5369.

2. Zhen Y, Liao L, Zhang H. Intestinal giardiasis disguised as ulcerative colitis. Case Rep Gastrointest Med. 2018;2018:8968976.

3. Heyworth MF. Giardia duodenalis genetic assemblages and hosts. Parasite. 2016;23:13.

4. Escobedo AA, Almirall P, Hanevik K, Cimerman S, Rodriguez-Morales AJ, Almanza C, et al. Giardiasis: a diagnosis that should be considered regardless of the setting. Epidemiol Infect. 2018;146:1216-8.

5. Soares R, Tasca T. Giardiasis: an update review on sensitivity and specificity of methods for laboratorial diagnosis. J Microbiol Methods. 2016;129:98-102.

6. Koehler AV, Jex AR, Haydon SR, Stevens MA, Gasser RB. Giardia/giardiasis - a perspective on diagnostic and analytical tools. Biotechnol Adv. 2014;32:280-9.

7. McElligott JT, Naaktgeboren C, Makuma-Massa H, Summer AP, Deal JL. Prevalence of intestinal protozoa in communities along the Lake Victoria region of Uganda. Int J Infect Dis. 2013;17:e658-9.

8. Al-Shehri H, Stanton MC, LaCourse JE, Atuhaire A, Arinaitwe M, Wamboko $A$, et al. An extensive burden of giardiasis associated with intestinal schistosomiasis and anaemia in school children on the shoreline of Lake Albert, Uganda. Trans R Soc Trop Med Hyg. 2016;110:597-603. 
9. Piepenburg O, Williams CH, Stemple DL, Armes NA. DNA detection using recombination proteins. PLoS Biol. 2006;4:e204.

10. Crannell ZA, Cabada MM, Castellanos-Gonzalez A, Irani A, White AC, Richards-Kortum R. Recombinase polymerase amplification-based assay to diagnose Giardia in stool samples. Am J Trop Med Hyg. 2015;92:583-7.

11. Elwin K, Fairclough HV, Hadfield SJ, Chalmers RM. Giardia duodenalis typing from stools: a comparison of three approaches to extracting DNA, and validation of a probe-based real-time PCR typing assay. J Med Microbiol. 2014;63:38-44

12. Smith C, McLachlan G, Al Shehri H, Adriko M, Arinaitwe M, Atuhaire A, et al. Schistosoma mansoni infection as a predictor of low aerobic capacity in Ugandan children. Am J Trop Med Hyg. 2019;100:1498-506.

13. Verweij JJ, Schinkel J, Laeijendecker D, van Rooyen MA, van Lieshout L, Polderman AM. Real-time PCR for the detection of Giardia lamblia. Mol Cell Probes. 2003;17:223-5.

14. Verweij JJ, Blange RA, Templeton K, Schinkel J, Brienen EA, van Rooyen MA, et al. Simultaneous detection of Entamoeba histolytica, Giardia lamblia, and Cryptosporidium parvum in fecal samples by using multiplex real-time PCR. J Clin Microbiol. 2004;42:1220-3.

15. Poulton K, Webster B. Development of a lateral flow recombinase polymerase assay for the diagnosis of Schistosoma mansoni infections. Anal Biochem. 2018;546:65-71.

16. Rostron P, Pennance T, Bakar F, Rollinson D, Knopp S, Allan F, et al. Development of a recombinase polymerase amplification (RPA) fluorescence assay for the detection of Schistosoma haematobium. Parasit Vectors. 2019;12:514.

17. Caccio SM, Lalle M, Svard SG. Host specificity in the Giardia duodenalis species complex. Infect Genet Evol. 2017;66:335-45.

18. Al-Shehri H, James LaCourse E, Klimach O, Kabatereine NB, Stothard JR. Molecular characterisation and taxon assemblage typing of giardiasis in primary school children living close to the shoreline of Lake Albert, Uganda. Parasite Epidemiol Control. 2019;4:e00074.

19. Moore CE, Elwin K, Phot N, Seng C, Mao S, Suy K, et al. Molecular characterization of Cryptosporidium species and Giardia duodenalis from symptomatic Cambodian children. PLoS Negl Trop Dis. 2016;10:e0004822.

20. GraczykTK, Bosco-Nizeyi J, Ssebide B, Thompson RC, Read C, Cranfield MR. Anthropozoonotic Giardia duodenalis genotype (assemblage) a infections in habitats of free-ranging human-habituated gorillas. Uganda. J Parasitol. 2002;88:905-9.

21. Johnston AR, Gillespie TR, Rwego IB, McLachlan TL, Kent AD, Goldberg TL. Molecular epidemiology of cross-species Giardia duodenalis transmission in western Uganda. PLoS Negl Trop Dis. 2010;4:e683.

22. Ankarklev J, Hestvik E, Lebbad M, Lindh J, Kaddu-Mulindwa DH, Andersson JO, et al. Common coinfections of Giardia intestinalis and Helicobacter pylori in non-symptomatic Ugandan children. PLoS Negl Trop Dis. 2012;6:e1780.

23. Nolan MJ, Unger M, Yeap YT, Rogers E, Millet I, Harman K, et al. Molecular characterisation of protist parasites in human-habituated mountain gorillas (Gorilla beringei beringei), humans and livestock, from Bwindi impenetrable National Park, Uganda. Parasit Vectors. 2017;10:340.

24. Hansen S, Roller M, Alslim LMA, Bohlken-Fascher S, Fechner K, Czerny CP, et al. Development of rapid extraction method of Mycobacterium avium subspecies paratuberculosis DNA from bovine stool samples. Diagnostics (Basel). 2019;9:36

\section{Publisher's Note}

Springer Nature remains neutral with regard to jurisdictional claims in published maps and institutional affiliations.
Ready to submit your research? Choose BMC and benefit from:

- fast, convenient online submission

- thorough peer review by experienced researchers in your field

- rapid publication on acceptance

- support for research data, including large and complex data types

- gold Open Access which fosters wider collaboration and increased citations

- maximum visibility for your research: over 100M website views per year

At BMC, research is always in progress.

Learn more biomedcentral.com/submissions 